Every child: In school and in class, every day and on time

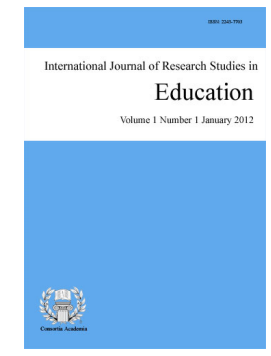

\title{
Abstract
}

Links between truancy and academic performance have been well established in research. As such, different measures have been employed to combat truancy across the world. Despite these struggles, current data accessed from different parts of the world show this problem to continue at different degrees. The objectives of the present research were twofold: First, to explore whether the number of students whose truancy is limited to part of the school day is less than those who miss the whole day. Secondly, the study aimed to study the practices of school-administrators in monitoring students' school-attendance and their impact on combating truancy. The results showed that: (i) there are truants of different types: those who miss whole school-day, those who miss some sessions and those who practice both types, (ii) school administrators rely on the same strategy of monitoring students' school-attendance regardless of the truancy-style that is predominant, (iii) in average, whole-day truants perform lower that those who missed part of the day; and, (iv) the prolonged use of the same strategies in monitoring truancy, especially if it is well-known by students has; and, (iv) the use of general and one strategy of monitoring truancy has little impact on schools' struggles to combat truancy. The study recommended educational experts and other stakeholders to categorize truants in their records, and use unique strategies to control different categories of truants.

Keywords: school attendance; absenteeism; truancy; Tanzania 


\section{Every child: In school and in class, every day and on time}

\section{Introduction}

Over the past years, a link between truancy and academic functioning (school attendance and performance) has been well documented in research. Although few studies have failed to establish a direct effect of truancy on students' performance (e.g., Chen \& Lin, 2008; Andrietti \& D'Addazio, 2012), there has been prolific literatures showing this relationship. Those who support existence of that relationship have shown that students with the highest truancy rates have the lowest academic achievement rates, and they have high dropout rates when compared to daily school attendees (Arulampalam, Naylor, \& Smith, 2008; Yahaya, Ramli, Hashim, \& Rahman, 2010; OECD, 2012; National Centre Brief, 2012; Mlowosa, Kalimang'asi, \& Mathias, 2014).

Although students are supposed to go to school and remain there till the end while attending all scheduled sessions, research shows that most of them do not make it. Many of the previous studies have widely documented cases of hundreds of thousands of school-children being absent from school (Shute \& Cooper, 2015). For example, a report provided by Loader (2014) showed that, in 2013 national absence rate in New Zealand was $10.1 \%$, and that figure lowered a little when compared to that of the previous year. In a similar way, result from PISSA 2012 study reported almost a same level of truancy in the OECD countries, putting the UK shockingly at the top (OECD, 2012).

\section{Theoretical underpinning}

The term 'truant' has its origin in the old French word 'trougant' (Shute \& Cooper, 2015). In the literally sense, the term was generally used to refer to someone who wanders from an appointed place. Being general in sense, we have more than not witnessed this term being used interchangeably with the term 'absentee' thereby referring to a student's failure from going to school or not being at a place where he/she was supposed to be within a school. Notwithstanding the similarities that the two concepts are sharing, it is technically and professionally incorrect to conceptualize them in that same way. This is because; there are specific 'qualifiers' which differentiate truancy from absenteeism. The distinction of the two terms is pertinent as it does not only help us to have a clear understanding regarding the characteristics that feature each of them, but also to have a clear picture regarding the specific extent to which each of them exists. This in-turn will help us as educational stakeholders to set problem-specific measures that can appropriately solve each of them.

In the education context both truants and an absentee are students who have failed to attend to school. As it was argued earlier, what differentiate them is the quality of the reason and not how long or how many times they have been missing from school. On the one hand, the literature defines an absentee as a student who has failed to attend to school but with permission from the school administration. Thus, regardless of the number of days a child missed classes, the reasons as to why he/she has failed to attend to school or a class are deemed genuine and are officially known. It needs to be acknowledged that school absenteeism cannot be denied. Due to some genuine reasons-including sickness-every now and then, students miss some school activities and lessons (Whitfield, 2010; Komakech \& Osuu, 2014). As such it only becomes a problem if a student misses a school without any official excuse. And when the permission for absence is not officially granted, the quality of that action changes from being absenteeism to truancy. Putting it in brief therefore, contrary to absenteeism, truancy is a situation where a student has failed to attend to school or a class-regardless of the number of days-without any permission from the school authority (National Centre for School Engagement-NCSE, 2006; Yahaya et al., 2010; Komakech \& Osuu, 2014; Van Breda, 2014).

More than not, the term truancy has been defined using the quantitative parameters in the literature. As such, the length of time or number of days a student has missed classes has been used to differentiate an absentee from 
a truant. This is the case with the terms such as 'chronic' or 'habitual' absenteeism are used to refer to truancy (Sutphen, Ford, \& Flahert, 2010; Shutte \& Cooper, 2015). They are typically applied when a student exceeds a specified number of unexcused absences over a certain period of time. The problem with quantification of the term is that different areas-be it in the same or different country-has been defining it differently and using different criteria to judge it. This is for example the case with the US where laws enacted to combat this same problem differ between the States (Sutphen, Ford, \& Flahert, 2010). It is the view of this article that this practice is incorrect because what qualifies an action to be labelled truancy is the state of being absent without official excuse and not the number of days or length of time someone has missed.

\subsection{The Problem}

Countries across the world have been employing a number of strategies to fight truancy among students. While in some countries, such as the US legal measures have been in use (Sutphen, Ford, \& Flahert, 2010); in some others, absenteeism has been fought through "traditional means" including mere identification of absentees and the subsequent home-to-home follow-ups (National Center Brief [NCB], 2012). However, despite of the use of different strategies to combat absenteeism, as it was shown earlier, this issue has been continuing to be recorded as one of the big problems (Loader, 2014; OECD, 2012; Tanzanian Ministry of Education and Vocational Training [MoEVT], (2014).

Next to the problem of using quantifiable indicators to define truancy is that there is a deficit of clarity regarding various styles through which truancy is behaved. Consequently, we do not have a definitive picture as to: (i) which among the type (styles) of truancy is more prevalent, (ii) the degree to which each type of truancy affect academic performance, and (iii) whether or not, the general methods used to control truancy are effective to all types of truants. As such, it was the opinion of this study that the continuing exponential increase of this problem is in-part influenced by our overlooking practice regarding these issues.

\subsection{Objectives and research questions}

Generally, the main objectives of this study was to document school-administrators' practice of taking students attendance records and its impact on combating students' conduct of truancy. To attain the main objective, the study specifically explored the strategies that the school-administrators were predominantly using to monitor students' attendance, and whether such practices were able to identify different types of truants or not. In line with this, the study sought to identify the type of truancy that is highly conducted and whether students' academic performance differs when different types of truancy are practiced. In order to attend these objective, this study was guided by the following overarching research questions:

$>\quad$ Is there any difference in number between whole-day truants and students who abscond some school sessions?

$>\quad$ Is there any difference in academic performance between students who regularly abscond part of the school sessions and those who regularly do not appear to school across the whole days?

$>\quad$ What are the strategies used by school teachers in taking record of students' attendances? To what extent do they help in combating truancy?

\subsection{Importance of this study}

As it was mentioned above, all the literatures reviewed by the research have managed to highlight the number of truancy cases across countries. However, they have failed to categorically provide us with a clear picture regarding the existence of different types of truancy behaviors among students. As such regardless of the type of truancy being practiced, instead of using type-specific measures, combating truancy for the past two decades has been through the use of the same strategies. Therefore, this study is helpful in providing us with a clear picture of not only regarding the general level of truancy, but also categories of truancy and their specific effects on academic performance. Lastly, this study provide scholars with some light regarding a need to use respective techniques in combating different type of truancy. 


\section{Methodology}

\subsection{Research paradigm}

In order to attain study objectives, triangulation of data was needed. Thus, to gain detailed information, both quantitative and qualitative methods were employed. Thus, this study employed a mixed study design.

\subsection{Sample and sampling technique}

Literature shows that truancy may stem from multiple, often interrelated factors, and that this behaviour is not practiced by a homogeneous group of students (Sutphen, 2010; Shute \& Cooper, 2012). As such, the choice of the sample should be guided by the well-established information regarding the context where this problem is prevalent. Grounded on this information, the decision of the sample was made on the basis of educational statistical census provided by (MoEVT, 2014) which shows that students in public schools practice more truancy than is more with the fourth and fifth graders than the students in the other grades. Therefore, the study was delimited to involve 200 fifth graders in primary public school alone.

In the process of selecting samples, cluster random sampling technique was used. Therefore, at first, four public schools in four different regions were randomly selected. Then, one stream of Grade Five was randomly selected from each school. A point to note is that, each of the selected grades had 50 students. Therefore, the total participants were 200 grade five students.

\subsection{Data collection instrument}

To allow triangulation of information and improve their reliability and validity, data collection was conducted by the use of two main strategies: document analysis and interview. While document exploration was conducted to get information regarding recorded attendance trends, and truants' academic performance, interviews, on the other hand, were conducted to collect information regarding teachers' attributes: what and how they do in monitoring students' school attendance; and, whether during the process of recording attendance, teachers are interested to know the reason for the student's school attendance failure, and the length of time a student has been missing. These, in a long run, were aimed: (i) to explore the extent to which teachers cared to note different styles of truancy; and, (ii) to get information regarding the extent to which attendance monitoring strategies that were used by teachers had an influence upon their school attendance decisions.

\subsection{Procedure}

The study was conducted in two stages: it began with interviewing the students and ended up with document exploration. In the process of interviewing students, only 60 grade-five students were selected to participate whereby each school contributed 15 participants through random sampling. This stage took one month to be completed with each school having been allocated one week of interview-visits. At the time these interviews were being conducted, the researcher perused some attendance registers and talked to some teachers. The sum of all these helped the researcher to note that teachers' attendance taking practice did not bother to categorize truants intro their respective types. Thus, class-teachers were trained and requested to categorize students who have failed to attend to school into their respective categories. The training was offered so ensure validity of data by ensuring attendance-taking teachers do not influence students' change of behavior. That is, avoiding the "Hawthorne effects ${ }^{l}$ in the conduct of research. According to Fraenkel, Wallen, Hyun (2012), during data collection, if there is an increase of attention on part of the data collector or when the practice of data collection influences a deviation of the situation from the normal, it is likely to positively affect behavioral change on part

\footnotetext{
1 The positive effect resulting from increased attention and recognition of subjects when some the practice deviates from the normal (Fraenkel, Wallen, Hyun 2012, p. 174)
} 
of the subjects. It is worthy to mention that a time-lapse of one month was allowed before the attendance records were collected for analysis. Along with exploring attendance records, it was at this time when truants' monthly examination scores in the three subjects (Math, English and Science) were also cross-checked. This therefore marked the second stage of data collection process which took approximately two weeks to complete.

\subsection{Planned data analysis}

Qualitative data collected from interview were coded and analyzed using content analysis techniques. This procedure is said to be helpful in establishing patterns of constructs that best explains: (i) teachers' and class leaders' behavior in taking note of students' truancy, and (ii) students' perceptions on the influence of attendance-records and attendance taking strategies predominantly used by the school administration on their attendance behavior. Then, attendance registers, and records of students' academic progress were analyzed to determine the degree of truancy, kind of truancy mostly recorded, and academic performance of all categories of truants.

\section{Results}

\subsection{Categories of truancy practiced in schools}

Generally, as it can be seen in chart 1, 51 cases of truancy were identified across the whole study time. Specifically, three categories of truants were identified: those who missed some sessions or part of the day, those who missed the whole day and those who practiced both. Putting it into more specific figures, on the one hand, results showed that, $32(16 \%)$ cases of students absconding one or several school sessions. Of these misers, 23 were cases of missing some class-session, and 9 were cases of students missing some co-curricular activities. On the other hand, a record showed $13(6.5 \%)$ cases of whole day truancy. The last group had truants who practiced both: whole-day truancy and that of some sessions. This was the smallest as it had only 6 (3\%) students. This shows that, students who do not attend to school the whole day are fewer as compared to those who attend but fail to remain at school till the end, or fail to attend all the sessions without any official excuse.

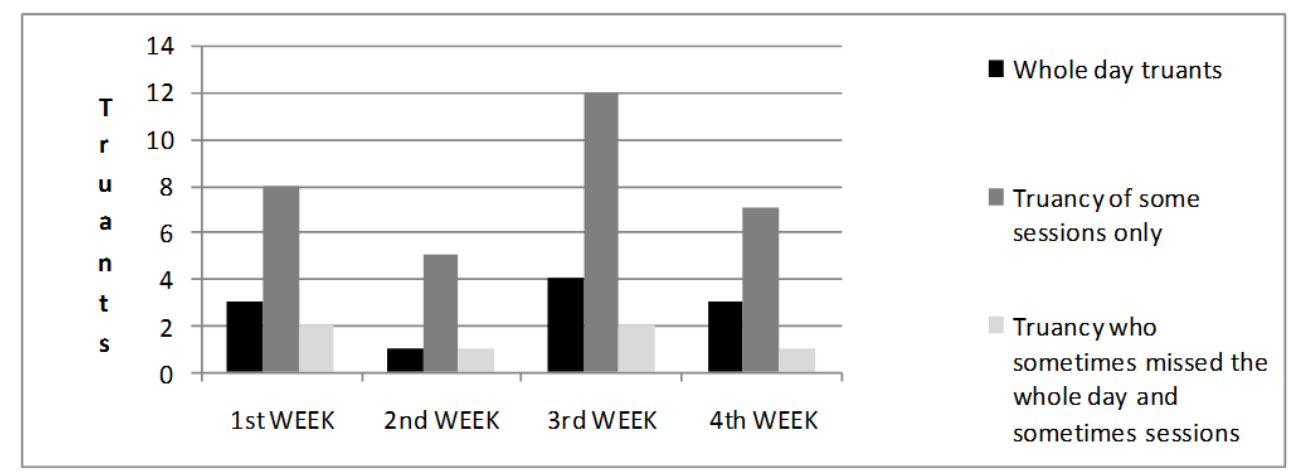

Figure 1. Categories of truancy committed at school

\subsection{Difference in performance between the different categories of truants}

Raw scores of students in a monthly test of three subjects (Mathematics, English and Science) were used to compare performances of students behaving three types of truancy. Each of such subjects was marked out of 50 points. Since the number of truants in each category was not equal, the researcher decided to select randomly six truants from each category for comparison. A decision to compare six truants from each class was based on the reason that the lowest number of truants noted in all the four grades was six. Then, sum of their scores in the three subjects mentioned above were compared. Results (see Table 1) showed that, students whose truancy is of the whole day had almost the same scores as those who committed other types of truancy. As it is seen in table 1, a little difference in performance was noted among the three categories. Nevertheless, those who missed some 
Makwinya, N. M.

secession had somewhat higher permanence compared to the others. Probably, this might be due to a possibility that truants in this group had missed one or few sessions; or, their truancy covered a short time.

\section{Table 1}

Difference in academic performance between the three categories of truants

\begin{tabular}{llcccc}
\hline \multicolumn{1}{c}{ Academic performance } & $n$ & $\begin{array}{c}\text { Sum of their } \\
\text { scores in } \\
\text { English }\end{array}$ & $\begin{array}{c}\text { Sum of their } \\
\text { Scores in } \\
\text { Mathematics }\end{array}$ & $\begin{array}{c}\text { Sum of their } \\
\text { scores in } \\
\text { Science }\end{array}$ & $\bar{X}$ \\
\hline Whole day truants & 6 & 201 & 175 & 162.5 & 179.5 \\
Practiced truancy of both types & 6 & 190 & 173 & 180 & 181 \\
Part-of-the day truants & 6 & 180 & 203 & 220 & 201 \\
\hline
\end{tabular}

\subsection{Teachers' practice in monitoring students' attendance}

Two types of information was collected regarding the attributes of the school administration - what and how they do - in monitoring students' school attendance and the type of attendance focused in their records. The summary of the coded interview response was put in figure 2 and figure 3 .

On one hand, students were asked to mention and describe predominant strategies used by their class teachers to record and monitor their daily school attendance. Summary of results are in figure 2. As it can be seen, of all 60 respondents, $25(41.7 \%)$ had a view that, the main strategy teachers use to monitor school attendance is by making a roll-call sometimes in a day. While their names were being called, if a candidate was available, he/she was supposed either to stand up or to respond vocally. Others 17 (28.3\%) argued that, their attendance is cross-checked by counting the number of exercise books they submit to one of the subject teachers for marking every day. The last group of respondents $12(20 \%)$ were those who said that, a class teacher (or monitors and monitress) distributed the official class register into the class and asked each one of them to sign next to his or her name.

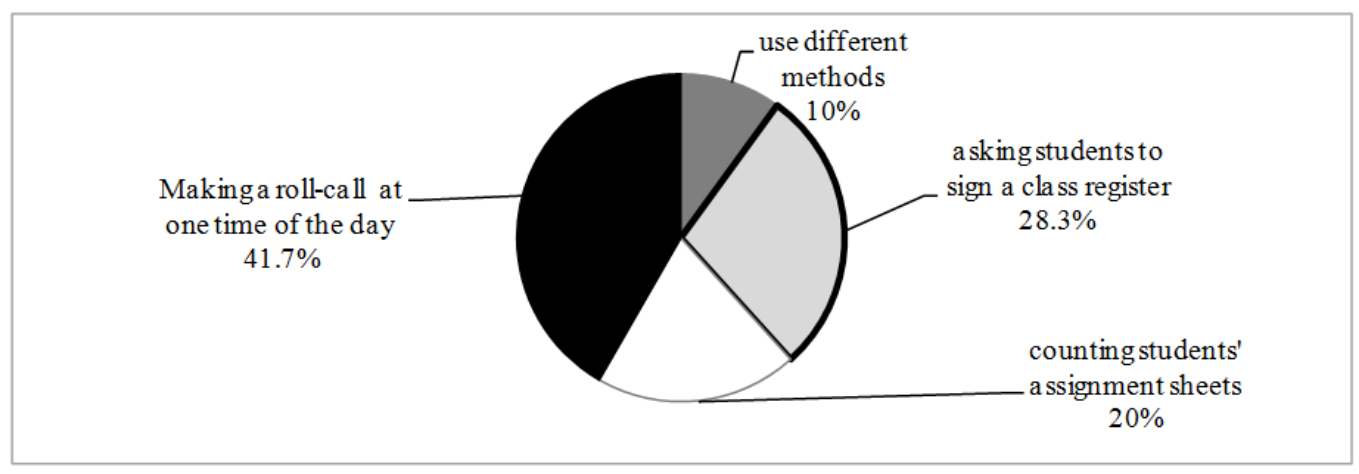

Figure 2. Strategies used to monitor students attendance

Contrary to the preceding views, very few participants $6(10 \%)$ told a researcher that their class teachers use different techniques of checking students' attendance. Sometimes, they enter a class and ask for the chronic truants to step before others, while the other times, they check their attendance by making a roll call. Thus, it is difficult for a student to predict how a teacher will assess their attendance.

On the other hand, regarding timing of recording students' attendance (see figure 3), students had a view that this is often done only once a day when they are at school. Specifically, 29 (48.3\%) respondents argued that this is conducted just before the end of the school sessions (in the evening), while 19 (31.7\%) of the respondents reported that this is done soon after they report to school (in the morning); and 12 (20\%) said check-up is conducted in the afternoon, soon after lunch break. Of all the interviewed participants, only one of them attracted a researchers' attention. This is because; this respondent had an experience of his class teacher to vary the time of recording attendance. He specifically said: 
"It is difficult to predict when roll calls will be made; before classes begin in the morning, this is the first thing the teacher-on-duty does. Then, attendance is taken soon after we resume classes in the afternoon session and.......... Therefore, attendance is often taken twice or thrice a day".

Because of uniqueness of this respondent compared to others, a researcher wanted to find out why he was an outlier. It was found that this student was transferred from a school outside this region in the past few months. Probably, this is a culture of monitoring attendance in the school he was enrolled before.

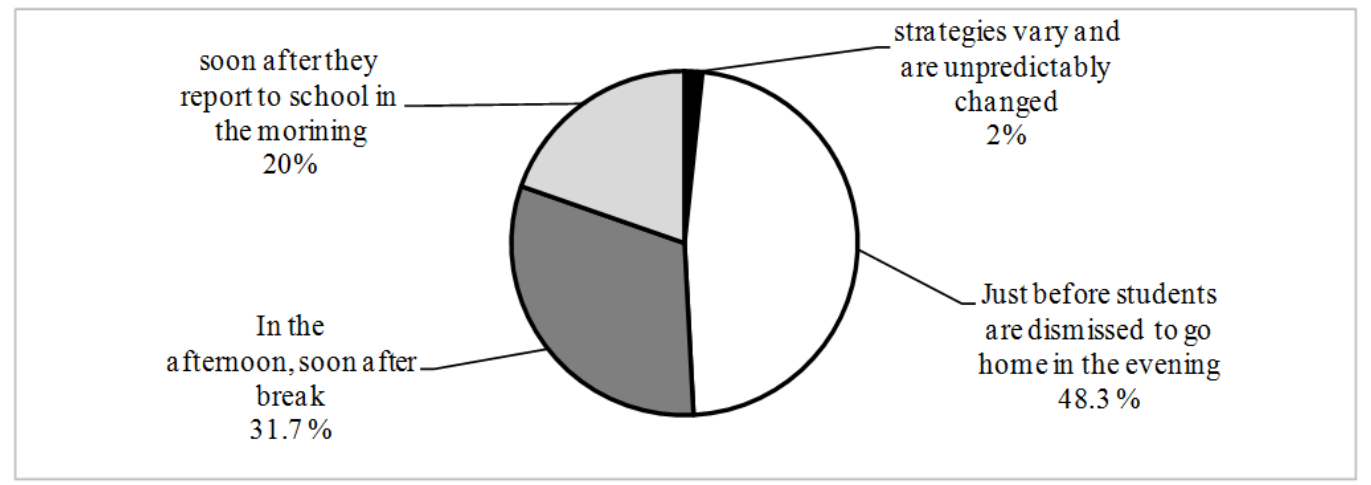

Figure 3. Timing of recording truancy

\subsection{Influence of attendance monitoring strategy on students' truancy}

Lastly, respondents were asked to provide their views regarding the influence of the attendance monitoring mechanism on their attendance behaviors. Interviews and responses picked from the participants were based in two main issues: how the uses of the strategies in question influence their attendance and their perception of what should be done to abolish truancy.

Regarding the first focus of the interview, many of the students had a view that they are used to the strategies such that they can tricky teachers and cheat them regarding their attendance in their registers. Specific example was picked from Juma (not his real name) who said:

"Uncle; you know what; to be sincere, the numbers of truants recorded by the class teachers is less than the actual number. Once you show up in the morning then it is over. When attendance is recorded in that morning, you can just go home sometime after recording is done. When attendance is recorded in the afternoon, if you are absent at the time attendance is taken, they simply assume your absence is genuine. More importantly, most of us are unaware that missing some of the day-schedules of the school without any official excuse is truancy ........”

This response was supported by Jacqueline (not her real name) who had this to say:

"Truants know how to win the teachers, since attendance is often taken at specific hours of the day, then, if it is done by calling our names, a friend from the class are set to respond that call. After all, it is just sound of the respondent that is considered and not his/her face.

Through that, truants win a game".

On the other hand, regarding their view of what is to be done for them to stop truancy, majority had a view that, truancy can only be shaped if three things are done: (i) parents are educated regarding their participation in monitoring their children, (ii) students are taught regarding the impact of truancy on their academic excellence and (iii) teachers are taught regarding the techniques useful to abolish truancy. For example, one of the respondents from grade five ' $\mathrm{B}$ ' had this to say: 
"Let me tell you Mr. Researcher; what matters is the knowledge regarding the consequences of this behavior. If you punish me without asking me why I miss from school regularly, and if you do not educate me regarding the consequence of this behavior, how do I stop it? Let me tell you, when I do not come to school, I usually have something to do - be it good or not to you".

What was so interesting was that, this respondent was one of the chronic whole day truants who missed at school 5 times last month.

\section{Discussion}

Due to its grievous consequences on the individual in particular and the society in general, this problem (i.e., truancy) is becoming the concern of every member of society. Findings of this study show a number of things.

One of the major findings of this study is existence of three types of truants: those who miss the whole day, those who miss some of the sessions and those who practice both styles of truancy putting cases of truancy by missing some school session at the top. These results are similar to those reported by Yahaya et al. (2010) who found school truancy, class-truancy and co-curricular truancy. Readers need to be reminded that, before data collection, a researcher confirmed-through document survey conducted before commencement of the study - that there is no culture of categorizing truants. With these findings, one would wish to ask her/himself as to why administrators are not categorizing truants in their records. Explanations put forward by Van Breda (2014) can help to answer this. According to him, administrators' failure to categorically report truancy might be caused by their little understanding regarding the conditions which qualify a student to be called a truant. Most likely, many teachers think that for a student to be called truant he/she must fail to attend to school across the whole day. Reporting the level of truancy without specifically categorizing types of truancy noted in schools has many negative consequences. One of them is that, this practice does not warrant us as stakeholders to set appropriate measures which will help to solve truancy. Experience shows that, because of that practice, we have been concentrating on the whole-day truants and ignore the other types of truants. Consequently, all the strategies that have been set especially at school levels had little success on unexcused misers of some school sessions. As s result, although we are a little successful in combating whole-day truancy, the rate of session-to-session truancy is increasing.

The second thing we learn from this study is that, the impact of truancy differs when different types of truancy are committed. However, this difference is not very significant. Under normal circumstances, one would expect those who miss the whole day to have performed lower than the other types of truants. However, in this study the case is different. Explanation that would help to clarify these findings is that, since mathematics, science and second language subjects are stereotyped to be difficult subjects by students, it is possible that these were the lesson sessions students were registered to miss mostly as compared to class sessions of other subjects. If therefore performance on other subjects apart from these ones would have been compared, possibly whole day truants would have performed lower than the rest. Generally, this shows therefore that both the frequency and the length of time a student misses at school have almost equally significant impact on the students' academic performance. This again helps to remind education experts on the impact of all types of truancy on students' academic excellence.

Finally, the study informs us regarding teachers' practice of monitoring attendance. Specifically, the study tells us that, when recording attendance, teachers use the same, same approaches, and more importantly recording of attendance is conducted in a fixed schedule. It is the view of the present study that this practice is unprofessional, and is likely to make us unsuccessful. We all know that decision to abscond a class or a session and decision to miss the whole day might be grounded on different reasons. These findings compliment to Thomas-Whitfield, (2010) argument that, on the surface, one would believe kids who skip school are stupid, bad, or can't handle the works but there is lot more that meets the eye in understanding why the skipping or absenteeism occurs. Therefore, if truancy of different types is to be abolished, then timing and strategies of 
recording attendance should be changed from time-to-time. As it was reported by respondents, if the same style is used, students develop a mechanism to cheat recorders. More importantly, if the focus is on the whole-day truancy, students develop a perception that missing some sessions is not truancy.

\section{Conclusion and implication}

Several conclusions can be developed from this study. One of them is that, at school, there are several types of truancy that is committed by students: those who abscond the whole day, those miss some sessions and those who practice both types of truancy. More importantly, connected to this is that, the impact of each type of truancy on academic performance is significant albeit with little differences between them. This implies that, regardless of the number of days a student misses schooling or the length of time he/she absconds, truancy continues to contribute significantly on students' low performance. Education stakeholders need to be reminded on the importance of putting more efforts in combating school truancy of all levels.

The second conclusion is that, when attendance is taken, teachers do not categorize students who have missed the whole day and those who have skipped some sessions. As such, it is difficult to determine the degree of each category of truancy. Consequently, attendance monitoring strategies which are predominantly used by the school administration do not help to influence students' decision of not to behave truancy. This implies that, if we want to abolish truancy, school administrators should collect information regarding truancy both in terms of levels and types. Connected to this practice, stakeholders should design unique mechanism of controlling each specific category of the identified truants.

As a summary, this study concludes and informs educational experts and other stakeholders that, students commit three types of truancy, and the effect of each of them on the educational functioning of a child is almost the same. As such, in an attempt to abolish truancy, information of both the degree at which truancy is committed and the type of truancy committed most often should be reported. This will help educational stakeholders to devise unique strategies to solve each of the identified categories of truants effectively.

\subsection{Recommendations for future studies}

One of the weaknesses of this study is based on its sample. It is important to note that truancy may stem from multiple, often inter-related factors, and that, this behavior is not practiced by a homogenous group of students. The present study used a small sample, covered a small area and involved public school students only. It is therefore recommended that, in order to gain a full picture of this phenomenon, other future studies should be conducted in private schools or in both private and public schools. But they should also cover a large area and involve a larger sample.

\section{References}

Andrietti, V., \& D’Addazio, R. (2012). Does class attendance affect academic performance? Evidence from “D’Annunzio" University. Retrieved from http://www.siecon.org/online/wp-content/uploads/2012/08/Andrietti-DAddazio.pdf

Arulampalam, W., Naylor, R. A., \& Smith, J. (2008). Am I missing something? The effects of absence from class on student performance. Retrieved from http://ftp.iza.org/dp3749.pdf

Chen, J., \& Lin, T. (2008) Class attendance and exam performance: A randomized experiment. Journal of Economic Education, 39(3), 213-227. http://dx.doi.org/10.3200/JECE.39.3.213-227

Fraenkel, J. R., Wallen, N. E., \& Hyun, H. H. (2012). How to design and evaluate research in education (8th Ed). New York, NY: McGraw-Hill.

Heilbrunn, J. (2007). Pieces of the truancy jigsaw: A literature review. Denver, CO: National Center for School Engagement.

Komakech, R. A., \& Osuu, J. R. (2014). Students' absenteeism: A silent killer of universal secondary education (use) in Uganda. International Journal of Education and Research, 2(10), 417-436. 
Makwinya, N. M.

Loader, M. (2014). Attendance in New Zealand schools in 2013. Retrieved from http://www.educationcounts.govt.nz/publications/series/2503/attendance-in-new-zealand-schools-in-20 $\underline{13}$

Ministry of Education and Vocational Training [MoEVT]. (2014). Basic education statistics 2013: National data. Retrieved from http://www.pmoralg.go.tz/noticeboard/tangazo-1023-20141229-Basic-Education-Statistics-BEST/FINA L-NATIONAL-27-MAY-2014.pdf

Mlowosa, T. P., Kalimang'asi, N., \& Mathias, B. D. (2014). The impacts of truancy in academic performance among secondary school students: A case study of Kigamboni Ward in Temeke Municipality. International Journal of Scientific and Research Publications, 4(11), 1-5.

National Center Brief (NCB). (2012). Truancy prevention efforts in school-community partnerships. Retrieved from http://www.promoteprevent.org/sites/www.promoteprevent.org/files/resources/Truancy\%20Prevention $\%$ 20Efforts\%20in\%20School_0.pdf

OECD. (2012) Results from the Programme for International Student assessment -PISA. Retrieved from http://www.oecd.org/pisa/keyfindings/PISA-2012-results-UK.pdf

Shute J. W., \& Cooper, B. S. (2015). Understanding in-school truancy. Phi Delta Kappan, 96(6), 65-68.

Sutphen, R. D., Ford, J. P., \& Flahert, C. (2010). Truancy interventions: A review of the research literature. Research on Social Work Practice, 20(2), 161-171.

Thomas-Whitfield, C (2010). Truancy intervention project: “Why don't they go to school?" Juvenile justice information exchange. Retrieved from http://jjie.org/back-school/

Van Breda, M. (2014). School truancy: Poor school attenders' perceptions of the impact regarding dysfunctional teacher-learner relationships on truant behaviour. Mediterranean Journal of Social Sciences, 5(23), 1056-1063. http://dx.doi.org/10.5901/mjss.2014.v5n23p1056

Yahaya, A., Ramli, J., Hashim, S., \& Rahman, R. (2010). The effects of various modes of absenteeism problem in school on the academic performance of students in secondary schools. European Journal of Social Sciences, 12(4), 624-638. 